\title{
MAGNETOCALORIC EFFECT IN CARBON-CONTAINING COMPOUNDS
}

\author{
Victor V. Korolev, Tatyana N. Lomova, Anna G. Ramazanova \\ G.A. Krestov Institute of Solutions Chemistry of RAS, http://www.isc-ras.ru \\ Ivanovo 153045, Russian Federation \\ vvk@isc-ras, tnl@isc-ras.ru,agr@isc-ras.ru
}

Abstract. The review is devoted to carbon-containing compounds with magnetic properties. It considers recent developments in the problem of synthesis and studying physico-chemical properties of single-molecule magnets (SMMs). It is shown that single-molecule magnets, such as graphene and its donor-acceptor complexes, metal complexes with Schiff's bases, paramagnetic high-spin complexes of porphyrins/phthalocyanines, as well as 3D nanoparticles of metal oxides and hybrid composites of magnetic nanoparticles with graphene have a large and even giant magnetocaloric effect at temperatures close to room conditions, i.e. beyond the temperature range of magnetic transitions. For the first time, the behaviour of such molecular materials has been determined by a direct method on an original microcalorimetric apparatus and the first data on the interconnection between the chemical structure of their molecules and magnetothermal properties have been obtained.

Keywords: single-molecule magnet, magnetocaloric effect, porphyrin, fullerene, graphene, Schiff's base

UDC 544.032.53

Bibliography - 84 references

Received 10.06.2019, accepted 21.06.2019

RENSIT, 2019, 11(2):199-216

DOI: $10.17725 /$ rensit.2019.11.199

CONTENTS

1. INTRODUCTION (199)

2. State-OF-the ART OF THE PROBlem OF MAGNETISM IN CARBON-CONTAINING COMPOUNDS (200)

3. Magnetocaloric efFect (MCE) IN PARAMAGNETIC COMPLEXES OF PORPHYRINS AND PHTHALOCYANINES (202)

4. MAGNETOTHERMAL PROPERTIES IN COMPOUNDS WITH SCHIFF's BASES (206)

5. MCE IN GRAPHENE AND OTHER CARBON NANOFORMS (208)

6. Conclusion (211)

ReferenCes (212)

\section{INTRODUCTION}

The last two decades have seen active studies of magnetocaloriceffect(MCE) invarious magnetically ordered materials [1, 2]. Magnetocaloric effect is an adiabatic change in the sample temperature at variations of external magnetic field. MCE is caused by redistribution of internal energy between the system of magnetic atoms and the material crystal lattice. The possibility to use MCE for creating a magnetic refrigerator that works at room temperature and in medical applications has urged quite a lot of research into this effect [35]. The list of works in this field contains several thousand papers and reviews. However, despite the large volume of the experimental data, the physical nature of MCE is not fully understood.

It is extremely important to study magnetocaloric effect in carbon-containing compounds that often display magnetic properties at the level of a simple molecule for solving fundamental problems of magnetism and solid state physics. This is connected with the problem of obtaining information about magnetic phase transitions and magnetic state of a substance [6]. Single-molecule magnets, such as graphene and its donor-acceptor complexes, metal complexes with Schiff's bases, paramagnetic high-spin complexes of porphyrins/phthalocyanines, as well as 3D nanoparticles of metal oxides and hybrid composites of magnetic nanoparticles with graphene have a large and even giant MCE at temperatures close to room conditions, i.e. beyond the temperature range of magnetic transitions. 
This review presents data on magnetocaloric behaviour of the above-mentioned molecular materials, the first data about the interconnection between the chemical structure of their molecules and magnetothermal properties.

\section{STATE-OF-THE-ART OR RECENT DEVELOPMENTS OF THE PROBLEM OF MAGNETISM IN CARBON- CONTAINING COMPOUNDS}

Carbon-containing compounds with magnetic properties have long been of interest to scientists. Materials of this new type with specific spintronics and quantum behavior at the level of a simple molecule were named single-molecule magnets (SMMs). Cooperation of chemists and physicists has allowed them to obtain a large volume of data about the interconnection of molecular structure and magnetic properties of objects and led to the formation of a new field in magnetochemistry. There are a number of research schools dealing with the problems of synthesis of SMMs (highspin molecules) and studying their electronic structure and magnetic properties [6-11]. One of the indicators of magnetic properties is the magnetocaloric effect (MCE) in a magnetic material. This effect has an extremely wide application range in magnetic cooling and therapy of cancer (in hyperthermia method applications). MCE is a change in the magnetic state of a material caused by changes in the external magnetic field. MCE is defined as a change in magnetic entropy in the isothermal process, $\Delta S_{\mathrm{m}}$ and/or as a temperature change in the adiabatic process following changes in the magnetic field, $\Delta T_{\text {ad }}$. MCE parameters can be obtained by directly measuring $\Delta T_{\text {ad }}$, or indirectly, by calculating $\Delta S_{\mathrm{m}}$ and/or $\Delta T_{\text {ad }}$ from experimental values of heat capacity and/or magnetization at different magnetic field values and temperatures. In most of the works, magnetocaloric effect of single-molecule magnets is determined in the low-temperature region (from 0 to $10 \mathrm{~K}$ ) from experimentally obtained data on the magnetization temperature dependence. All the attempts made so far to obtain maximum MCE values in the magnetic transition region for single-molecule magnets by the direct calorimetric

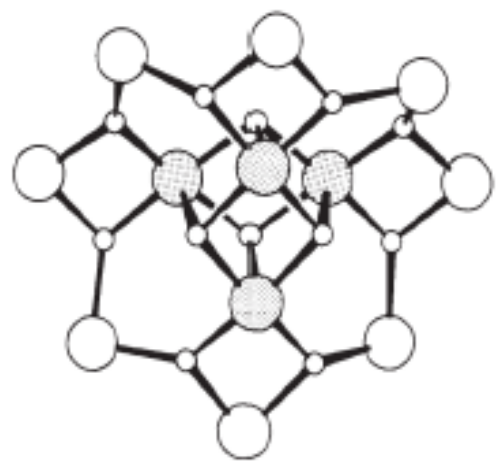

Fig. 1. Scheme of the $M n_{12}$ cluster structure [7]. method have been unsuccessful. However, it is at room temperatures that devices and apparatuses that use magnetocaloric effect work, not taking into account devices for specific purposes.

Among the first research groups who studied the crystal structure and magnetic properties of high-spin manganese clusters was $R$. Sessolli's group [7]. It was one of the first attempts of targeted design of a single-molecule magnet (Fig. 1). Later, studies of this type became much more numerous.

The magnetocaloric effect of $\mathrm{Mn}_{122}$ Cl-benzoate was calculated by the authors of [12] based on the temperature dependence of magnetization (from 2 to $20 \mathrm{~K}$ ), and at the magnetic flux density of $3 \mathrm{~T}$ it equals $15 \mathrm{~J} / \mathrm{mol} \mathrm{K}$.

Work [13] deals with synthesis, description and analysis of single-molecule magnets containing gadolinium and dysprosium. The authors of [13] study the magnetocaloric effect in gadolinium compounds using the characteristics obtained on a SQUID magnetometer. An example of the structure of the compounds that they obtained is shown in Fig. 2.

J. Schnack's group [14] studied the magnetothermal properties of antiferromagnetic single-molecule

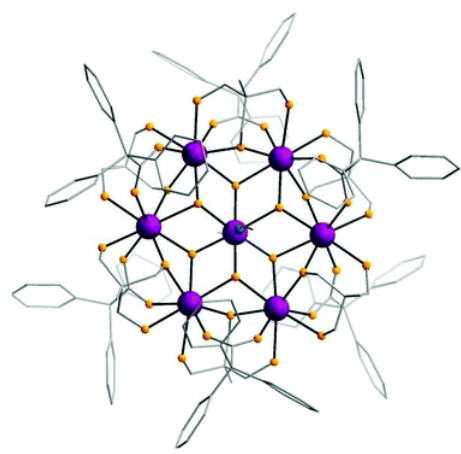

Fig. 2. Structure of $\left[\mathrm{Gd}_{7}(\mathrm{OH})_{6}\left(\mathrm{thmeH}_{2}\right)_{5}(\right.$ thmeH $)$ (tpa) $\left.{ }_{6}(\mathrm{MeCN})_{2}\right]^{2+}[13]$. 
magnets. They have found that deformations in the geometric structure of an antiferromagnetic increase the magnetocaloric effect.

When studying the magnetothermal properties of the dimer $\left[\left(\mathrm{Gd}(\mathrm{OAc})_{3}\left(\mathrm{H}_{2} \mathrm{O}\right)_{2}\right)_{2}\right] \cdot 4 \mathrm{H}_{2} \mathrm{O}$, the authors of [11] calculated the MCE from experimental data using the temperature dependence of specific heat capacity. At a temperature of $1.8 \mathrm{~K}, \Delta \mathrm{S}_{\mathrm{m}}$ was equal to $40 \mathrm{~J} / \mathrm{kg} \mathrm{K}$ $(B=7 T)$. The calculated MCE value of the dimer exceeded $\Delta T_{a d}$ of metallic gadolinium.

A large group of Chinese scientists [15] is studying the magnetothermal properties of clusters of rare-earth metals and their complexes with transition $3 \mathrm{~d}$ metals based on complex organic acids and other macromolecules. For example, they found a giant magnetocaloric effect in the $\mathrm{Gd}(\mathrm{OH}) \mathrm{CO}_{3}$ monocrystal of rhombic structure.

The authors of [16] have synthesized singlemolecule magnets based on Mn(II)-Gd(III) and discovered that the magnetism type depends on the compound structure. The entropy change value calculated by the authors using magnetization data at a temperature of 3-8 $\mathrm{K}$ and induction of $5 \mathrm{~T}$ exceeds the experimental data that were reported in literature earlier.

A tubular, 48-metallic (3d-4f) cluster of $\mathrm{Gd}_{36} \mathrm{Ni}_{12}$ was synthesized in [17] via self-assembly of the metal ions. The authors of the mentioned work calculated the entropy change $\Delta S_{\mathrm{m}}$ at different values of magnetic field and temperature and arrived at the value of $36.3 \mathrm{~J} / \mathrm{kg} \mathrm{K}$ at $3 \mathrm{~K}$ for $B=7 \mathrm{~T}$. This value is $45 \%$ higher than the highest value reported in literature $(25 \mathrm{~J} / \mathrm{kg} \mathrm{K})$ calculated by the same method for $\mathrm{Mn}_{14}$, [18] but is lower than the value calculated by Evangelisti based on heat capacity [11].

The latest achievements in the field of studying magnetic and magnetocaloric properties in ternary intermetallic compounds of rare earth elements $\mathrm{RE}_{2} \mathrm{~T}_{2} \mathrm{X}$ (RE - Gd-Tm; $\mathrm{T}=\mathrm{Cu}, \mathrm{Ni}, \mathrm{Co}$; and $\mathrm{X}$ $=\mathrm{Cd}, \mathrm{In}, \mathrm{Ga}, \mathrm{Sn}, \mathrm{Al}$ ) are considered in review [19]. Some of these compounds have a high MCE making them attractive in low-temperature magnetic cooling applications. The focus of the work is to understand the connections between magnetocaloric characteristics of the compounds, their crystal structure, magnetism and magnetic phase transition. The review discusses the physics of MCE appearance and potential applications of the $\mathrm{RE}_{2} \mathrm{~T}_{2} \mathrm{X}$ compounds.

Naoto Ishikawa [20] has published a number of works on studying the behaviour of phthalocyanine complexes of lanthanides as SMMs. The work confirms the contributions to the magnetic behaviour of the complexes made by the interaction of magnetic moments of the spin density carrier - lanthanide - with magnetic moments of the $\pi$-systems of the macrocyclic ligands in the complexes.

The authors of several recent publications report on the magnetocaloric effect for unique single-molecule magnets $\left\{\left[\mathrm{Mn}(\text { pyrazole })_{4}\right]_{2}\left[\mathrm{Nb}(\mathrm{CN})_{8}\right] \cdot 4 \mathrm{H}_{2} \mathrm{O}\right\}_{\mathrm{n}} \quad$ and $\left[\mathrm{Fe}(\text { pyrazole })_{4}\right]_{2}\left[\mathrm{Nb}(\mathrm{CN})_{8}\right] \cdot 4 \mathrm{H}_{2} \mathrm{O}$. In works $[5,21]$, the authors calculated changes in the isothermal entropy and the adiabatic temperature change by using the results of heat capacity measurements. They have found that these values are comparable with the data obtained for other representatives of single-molecule magnets. This conclusion also agrees with the results of the first study [22] of this compound that used an indirect approach for determining MCE.

The nature of molecular magnetism was studied by the authors of [23] on heterometallic 3d-4f SMMs. It was shown that the SMM properties depend on a combination of single-ion anisotropies of all the centers of the paramagnetic metal involved and presence of $3 \mathrm{~d}-4 \mathrm{f}$ exchange interactions. That is why it is necessary to take into account the internal properties of the d-metal ions involved and the role played by the contributions of both $\mathrm{d}$ and $\mathrm{f}$ electrons of the participating trivalent lanthanide ions.

The transition from a low spin to a high one caused by the intramolecular transfer of the electron was described in detail when the static magnetic properties and spin dynamics in zerosized valence cobalt tautomers was were studied [24]. It was shown that a spin-crossover can be controlled by temperature, external pressure or light radiation. 
The magnetic properties of finite graphene fragments of arbitrary shape were studied using benzenoid graph theory and first-principles electronic structure calculations. It has been demonstrated that the principle of topological frustration of the $\pi$-bonds can be used for introducing a large spin and for interesting spin distributions in graphene.

Weak supermagnetism and hysteresis at room temperature were determined for graphite oxide and reduced graphene oxide [27] (MCE, however, was not found). The magnetic behaviour was explained by individual domains, each representing a cluster of defective magnetic moments bound by a ferromagnetic interaction.

The authors of this review in their works discussed below considered the causes of MCE appearance in single-molecule magnets graphene and its donor-acceptor complexes, metal complexes with Schiff's bases, paramagnetic highspin complexes of porphyrins/phthalocyanines and their donor-acceptor dyads with substituted fullerenes - at the quantitative level. The magnetocaloric behaviour of the compounds at temperatures close to room conditions was studied. It was shown that, like $3 D$ nanoparticles of metal oxides and hybrid composites of magnetic nanoparticles with graphene, singlemolecule magnets have a large and even giant MCE. For the first time, the magentocaloric behaviour of such molecular materials was determined by a direct method on an original [28] microcalorimetric apparatus and the first data about the interconnection between the chemical structure of their molecules and magnetothermal properties were obtained.

\section{MCE IN PARAMAGNETIC COMPLEXES OF PORPHYRINS AND PHTHALOCYANINES}

Presence of a paramagnetic metal ion in the axially coordinated metalporphyrins leads to paramagnetism of their molecules and substances, which is reflected in the NMR spectra and nonindifference to magnetic fields. $\mathrm{Mn}(\mathrm{III}), \mathrm{Fe}(\mathrm{III})$, $\mathrm{Co}(\mathrm{II})$ and $\mathrm{Ln}$ (III) complexes possess a magnetic moment. Since there is a polarizable electron-excess aromatic $\pi$-system in the complexes, the spin density of the central atom is delocalized, which allows "controlling" their paramagnetic properties. It is especially true in cases when, along with a paramagnetic centre - a metal cation - the molecule has an additional centre with a non-zero spin. Since all paramagnetic materials display this effect, the goal is to find compounds with a large and giant MCE.

The results of the studies of molecular magnetism obtained since the time when this new field of magnetochemistry began to develop are presented in comprehensive review [29]. The work was devoted to the studies of the structure, synthesis, composition, magnetic properties and applicability of magnetic 3d, 3d-4f and 4f-coolants in different spheres of activity. Homometallic gadolinium compounds were studied in different clusters where the values of the magnetic component of the entropy change $-\Delta S_{m}$, which is a measure of MCE, reached about $27 \mathrm{~J} / \mathrm{kg}$ at 5 $\mathrm{K}$ and changes of magnetic field from 0 to $1 \mathrm{~T}$. Thus, studying zero-sized lanthanides(III) "built" into the coordination sphere of the tetrapyrrole macrocycle is a new field of research with only a small number of studies which include, in addition to the works on SMMs that were partially quoted in the previous section, our research into magnetocaloric properties of paramagnetic metalloporphyrins/metal phthalocyanines [30-40].

The measurements of MCE and heat capacity of the complexes of metalloporphyrins/metal phthalocyanines were made on an automated microcalorimetric unit with an isothermal shell [28]. The microcalorimetric measurement cell with a solid magnetic sample filled to the full volume with water together with the isothermal shell were placed into the pole gap $(60 \mathrm{~mm})$ of an electromagnet, which allowed determining the values of MCE and specific heat capacity in magnetic fields of $0-1.0 \mathrm{~T}$ at temperatures of 278-343 K. Adiabatic magnetization was achieved by quickly varying the magnetic field. The variations of temperature in the thermostatically controlled calorimetric cell during the calorimetric experiment were \pm 0.0002 . The error in the measurements of MCE and heat capacity was 1 


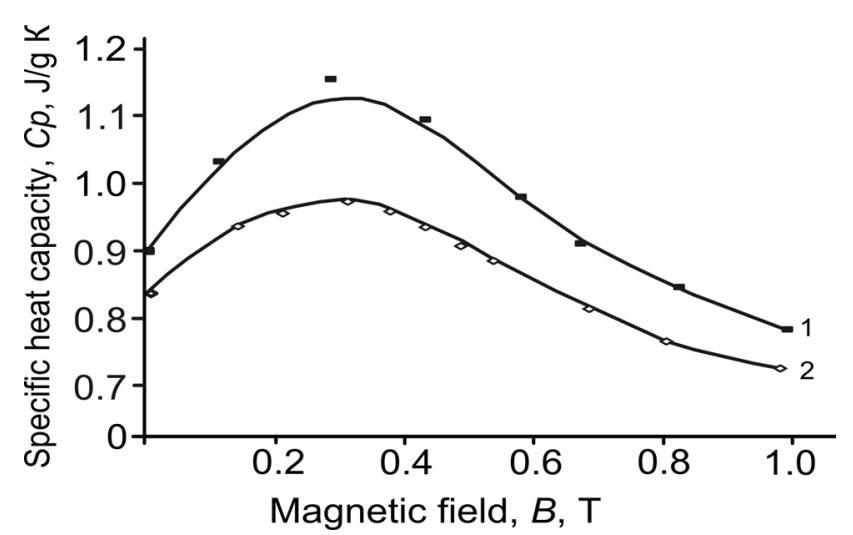

Fig. 3. Field dependence of specific heat capacity of $(A c \mathrm{O})$ $\mathrm{Mn}\left(\mathrm{p}^{-} \mathrm{-} \mathrm{BuPh}\right){ }_{8} \mathrm{TAP}(1)$ and (Cl)MnOEP (2) at $298 \mathrm{~K}$.

and $2 \%$, respectively. Besides, the experimental measurement of the specific heat capacity of the solid samples was made by the DSC method with a DSC 204 F1 Phoenix (NETZSCH).

We have studied the magnetocaloric effect and heat capacity of 20 functionalized metalloporphyrins/metal phthalocyanines (Fig. 3 and 4) (with the composition (X)MeY, where $\mathrm{X}=$ $\mathrm{Cl}, \mathrm{Br}, \mathrm{AcO}, \mathrm{Acac} ; \mathrm{Me}=\mathrm{Mn}, \mathrm{Eu}, \mathrm{Tm}, \mathrm{Gd}, \mathrm{Fe}$, $\left.\mathrm{Yb}, \mathrm{Tb} ; \mathrm{Y}=\mathrm{OEP}, \mathrm{TPP}, \mathrm{Pc},\left(\mathrm{p}{ }^{-} \mathrm{B} \mathrm{BPh}\right)_{8} \mathrm{TAP}\right)$. An example of their formula is given below (Fig. 4.1) at the temperature of $270-350 \mathrm{~K}$ and magnetic induction $0-1 T[30-40,41]$.

The MCE values in manganese(III) complexes at temperatures close to room conditions and magnetic induction of 1.0 Tare equal to $0.047-0.85$ $\mathrm{K}$, which makes them promising environmentallyfriendly materials capable of magnetic cooling and hyperthermia (with possible applications in early cancer detection, magnetic resonance imaging and magnetic cell separation).

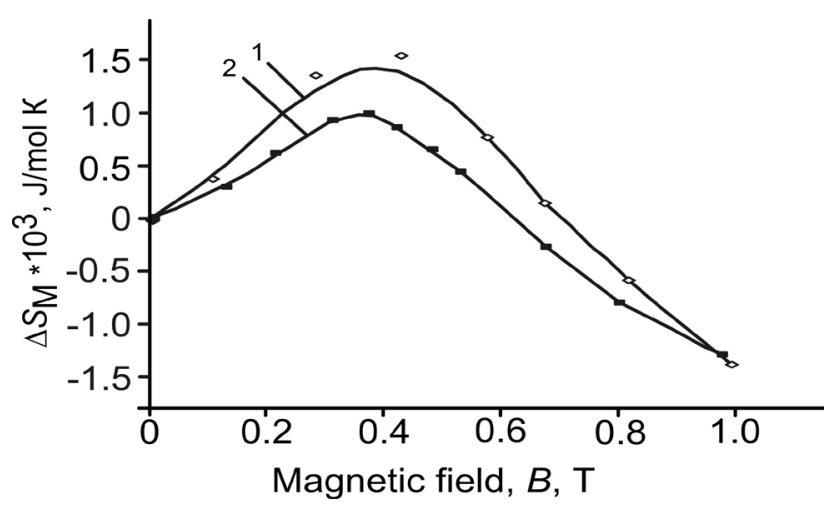

Fig. 4. Field dependence of changes in the entropy magnetic component of $(\mathrm{AcO}) \mathrm{Mn}\left(\mathrm{p}^{-} \mathrm{B} \mathrm{BuPh}\right)_{8} \mathrm{TAP}$ (1) and (Cl) $\mathrm{MnOEP}(2)$ at $298 \mathrm{~K}$.

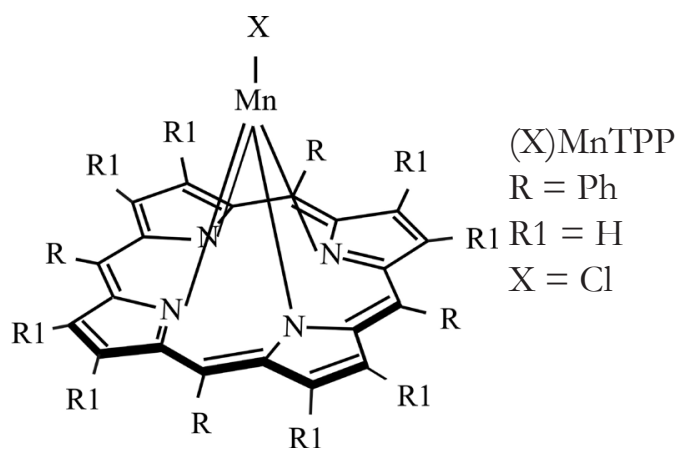

Fig. 4.1. Structure of the manganese(III)porphyrin complex.

The MCE of the complexes is positive over the whole range of magnetic field values and increases nonlinearly as the magnetic field grows. Such MCE behaviour is explained by the paramagnetic properties in manganese complexes. The largest MCE is found in (Cl)MnOEP. The lowest MCE values are observed in the complex with an acetate axial ligand. It means that the magnetocaloric effect is influenced by the nature of the substituent in the macrocycle, while the acetate ligand nature has a less significant effect. The MCE reaction to the nature of the complex is explained by the differences in the mutual position of the energy of the d-orbitals in the field of the ligands [37].

The MCE of the porphyrin tetraderivative (AcO) Mn(p- $\left.{ }^{\mathrm{B}} \mathrm{BuPh}\right)_{8} \mathrm{TAP}[36]$ is lower than that of the unsubstituted (in the mesoposition) analogs.

MCE, like magnetic susceptibility of porphyrin complexes, is connected with the oxidation state and spin configuration of the metal ion. That is why the effect of modifications of the macrocycle structure in the complex on the magnetocaloric properties was explained by the results of the experiments on describing the electron structure of the complexes [40].

For the complexes of europium, thulium and gadolinium with $\mathrm{H}_{2}$ TPP and an acetate- or chloride-ion as the axial ligand [39, 40], we have found that the $\mathrm{MCE}\left(\Delta T_{\mathrm{MCE}}\right)$ is equal to 0.127 $1.45 \mathrm{~K}$ at temperatures close to $298 \mathrm{~K}$ in magnetic field varying from 0 to $1.0 \mathrm{~T}$. In case of $(\mathrm{Cl})$ GdTPP, the MCE is practically independent of temperature.

For the Gd porphyrin acetate complex, the MCE is much higher than for the chloride one. At temperatures of $275-300 \mathrm{~K}$, the MCE values decrease in the following order: $\mathrm{Eu}>\mathrm{Gd}>\mathrm{Tm}$ 
in the chloride complexes of $(\mathrm{Cl}) \mathrm{LnTPP}$. Since the strength of binding $\mathrm{X}^{-}$acidoligands in (X)LnTPP is unknown, the differences in the MCE of the two complexes are explained by the macrocylce binding strength in the complexes depending on the nature of the axial ligand. The transition from the chloride complex (Cl)GdTPP to the acetate analog with bidentate coordination of the $\mathrm{AcO}^{-}$ anion is evidently accompanied by a shift in the central ion from the macrocycle plane and spin strengthening.

Unlike $\mathrm{Gd}(\mathrm{III})$ complexes, in lanthanide complexes with an asymmetrically filled f-shell, the electronic factor ( $\pi$-backdonation) begins to prevail over the geometric one. As it has been mentioned, at temperatures of $275-300 \mathrm{~K}$, the MCE decreases in the series $\mathrm{Eu}>\mathrm{Gd}>\mathrm{Tm}$, despite a more planar position of the lanthanide ion in the porphyrin plane in the same series due to the effect of "lanthanide contraction". The (Cl)EuTPP complex is an example of how the presence of $\pi$-backdonations between the central atom and the macrocycle does not lead to "compensation" of the spin, but makes it stronger. Thus, the electron configuration of the lanthanide ion in (X)LnTPP determines both the spin state of the spin-carrier itself and the degree of its delocalization due to the $\pi$-backdonations in the complex.

Judging by the quantitative data, axial ligand variations are still a more significant factor in regulating magnetothermal properties of (X) LnTPP than changing the lanthanide nature. That is why further research was into the magnetocaloric properties of acetylacetonate

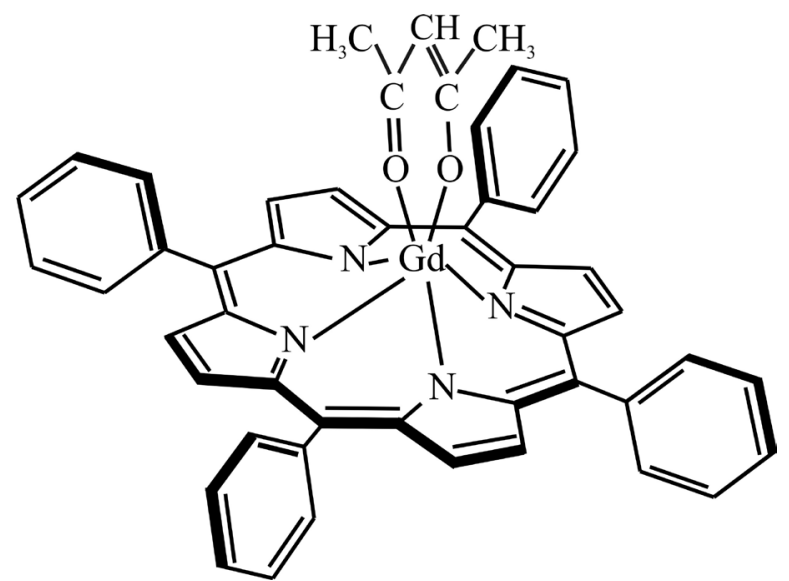

Fig. 4.2. (Acac) GdTPP complex structure. complex gadolinium(III)tetraphenylporphin (Fig. 4.2) [31, 34].

The effect of the axial acetylacetonate in magnetothermal properties of (porphyrinato) gadolinium(III) manifested itself in a specific temperature dependence of specific heat capacity measured directly and a low maximum on the MCE temperature dependence curves at $305-$ $310 \mathrm{~K}$. The specific heat capacity increases as the temperature rises, while the magnetic field effect is not reflected on the temperature dependence.

The MCE of (Acac)GdTPP is by 2 - 4 times lower in magnitude than in the acetate complex of gadolinium(III)tetraphenylporphin and one and a half times lower than in the chloride complex. The magnetocaloric properties become weaker due to the formation of a six-member aromatic cycle in case of bidentate coordination of the axial ligand, which leads to the formation of $\mathrm{O} \rightarrow \mathrm{N}$ $\pi$-backdonation and reduces the MCE.

Rare earth element complexes with porphyrins and phthalocyanines as paramagnetic materials have a large magnetocaloric effect (up to $1.45 \mathrm{~K}$ when the magnetic induction changes from 0 to 1.0 T) at the temperatures close to room conditions, which can be used for cooling in domestic and industrial refrigerators and other devices. As environmentally friendly paramagnetics, complexes of this class can replace the toxic compounds used in the steam compression cycle. (Porphyrinato)and (phthalocyaninato)gadolinium(III) complexes contain only a small percentage of expensive gadolinium in comparison with polycrystalline gadolinium. They are soluble in organic media, which makes it possible to form nanostructures of a higher order from these molecules. Since porphyrins, phthalocyanines and their complexes can selectively get accumulated in a tumour of a living body, the considered complexes have good prospects in widening hyperthermia applications in cancer detection and therapy. And, finally, an important thing, in terms of their advantages over paramagnetics, is that we can control their magnetocaloric properties by modifying their molecule structure.

A known strategy of strengthening spin properties is combining in one molecule a 


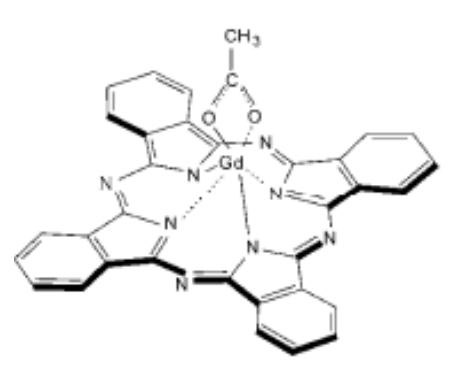

(a)

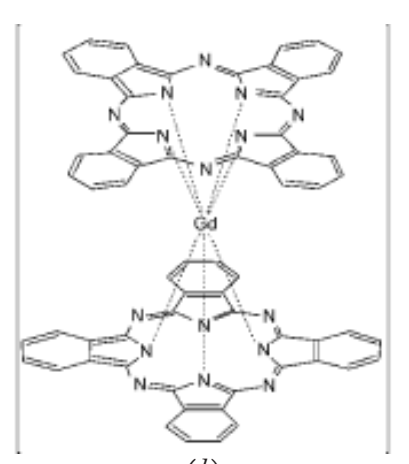

(b)
Fig. 4.3. Structure of the complexes: a) $(A c O) G d P$; b) $G d P c_{2}$ :

spin-carrier and a fragment for spin coupling (overlapping). A similar strategy was used for a paramagnetic - a double-decker oneelectron oxidized gadolinium complex whose magnetocaloric properties are described in works $[31,32]$ in comparison with the corresponding 1:1 complex (formulae (AcO)GdPc and $\mathrm{GdPc}_{2}{ }^{\circ}$, (Fig. 4.3) respectively).

The main spin-carrier in the double-decker complex is the central gadolinium atom. In addition to the paramagnetic $\mathrm{Gd}$ ion, a $\mathrm{GdPc}_{2} \cdot$ molecule contains one unpaired electron delocalized on one of the macrocycles, which gives hope that the magnetocaloric properties of the complex are better than in the (AcO)GdPc analog.

The temperature dependence of the doubledecker complex heat capacity, in contrast to the monophthalocyanine analog, has one pronounced maximum. The character of MCE changes following temperature variations is determined by the temperature dependence of specific heat capacity (Fig. 5 and 6). Contrary to expectations, the MCE values in $\mathrm{GdPc}_{2}$ are much lower than in (AcO)GdPc. The MCE temperature dependence

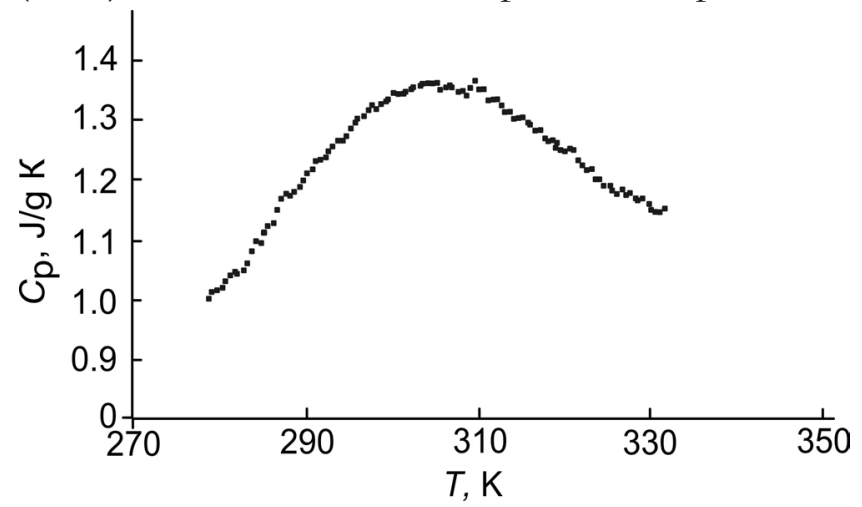

Fig. 5. Temperature dependence of specific heat capacity $\left(C_{p}\right)$ of $\mathrm{GdPc}_{2}$ in zero magnetic field.

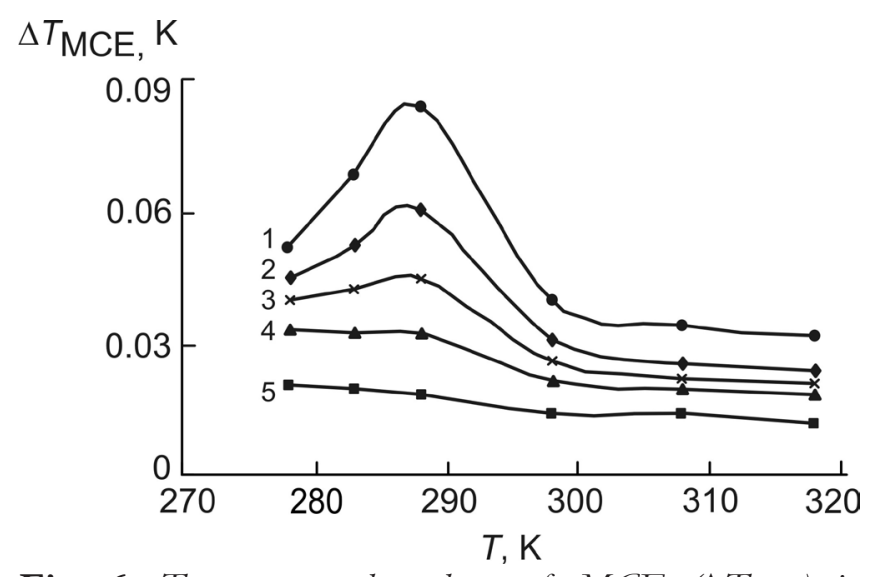

Fig. 6. Temperature dependence of MCE $\left(\Delta T_{M C E}\right)$ in $\mathrm{GdP}_{2}{ }^{\circ}$ at magnetic induction (1) 1.0 , (2) 0.8 , (3) 0.6 , (4) 0.4, (5) $0.2 \mathrm{~T}$.

in $\mathrm{GdPc}_{2}{ }^{\cdot}$ has a maximum at $288 \mathrm{~K}$ increasing with the growth in magnetic induction.

Lower MCE values in the series (AcO)GdTPP, $(\mathrm{AcO}) \mathrm{GdPc}, \mathrm{GdPc}_{2}{ }^{\cdot}$ have allowed us to evaluate the ratio of contributions of the ferromagnetic and antiferromagnetic components to the magnetic behaviour of the $\mathrm{GdPc}_{2}{ }^{\circ}$ complex. It has been concluded that their MCE is associated with changes in the electron subsystem. Thus, in the double-decker complex, instead of the expected strengthening of spin properties, these properties become weaker, which is only possible when the intermolecular antiferromagnetic coupling prevails over the intramolecular one.

Depending on the electronic configuration, metal-ligand $\pi$-backdonation becomes the dominant factor of delocalization of spin density in case of lanthanide complexes with asymmetrically filled $f$-shells $\left(\mathrm{N} \rightarrow\right.$ Eu $\left(f^{\circ}\right)$ in case of $(\mathrm{Cl})$ EuTPP, $\mathrm{N} \leftarrow \operatorname{Tm}\left(f^{2}\right)$ in case of $\left.(\mathrm{Cl}) \operatorname{TmPc}\right)$.

\section{MAGNETOTHERMAL PROPERTIES IN COMPOUNDS WITH SCHIFF'S BASES}

An important place among single-molecule magnets is taken by iron(III) complexes with Schiff's bases ( $d^{5}$ electronic configuration) as the most stable spin-variable systems [43]. By modifying the ligand chemical structure it is possible to control the magnetic behaviour of the whole complex. In practice, combining liquid crystal and spin-variable behaviour in one material seems quite relevant and promising. The authors of work [44] managed to synthesize a complex that possesses magnetic anisotropy and 
depends on the magnetic field in the mesophase. Such materials can be applied as active media for storage and optical devices. Scientists have so far synthesized a number of metal mesogens with the following properties: electric (linear conductors) [45], electro-optical (ferroelectric liquid crystals) [46], optical (strong birefringence, dichroism, nonlinear optical behaviour) [47] and magnetic (paramagnetic liquid crystals, molecule orientation control in magnetic field) [48].

Among the works published around the world there is not a single one devoted to experimental studies of magnetothermal properties of iron(III) azomethine complexes in the region of room temperatures. There are only several works in which the authors conducted a theoretical study of magnetic phase transitions in spin-variable systems [49] or made experimental studies in the region of low (up to $100 \mathrm{~K}$ ) temperatures [50].

Thanks to their biological activity, iron(III) complexes with Schiff's bases play an important role in medicine [51], as models of iron-containing enzymes in coordination chemistry [52]. Researchers pay special attention to mixed-ligand complexes (that contain $\mathrm{N}, \mathrm{O}$ and/or $\mathrm{S}$ donor atoms) because of their anti-tumour, antifungal and antibacterial activity [53]. Quite interesting are the works aiming to determine the types of ligands that tend to form metal complexes with magnetic properties. Some works represent studies of bischelate hexacoordinate iron(III) complexes with Schiff's bases but their liquid crystal analogs have been obtained comparatively recently.

An experimental study of magnetothermal properties of iron(III) complexes with Schiff's bases was for the first time conducted by the calorimetric method in magnetic fields from 0 to $1.0 \mathrm{~T}$ in the temperature range of $278-320 \mathrm{~K}$ in [54]. As a result, the authors determined the specific heat capacity and magnetocaloric effect of several bis-chelate iron(III) complexes based on azomethine 4,4'-dodecyloxybenzoyloxybenzoyl4-salicylidene-2-aminopyridine (complexes: (1) - $\mathrm{C}_{76} \mathrm{H}_{82} \mathrm{~N}_{4} \mathrm{O}_{12} \mathrm{Fe} \cdot \mathrm{NO}_{3},(2)-\mathrm{C}_{76} \mathrm{H}_{82} \mathrm{~N}_{4} \mathrm{O}_{12} \mathrm{Fe} \cdot \mathrm{PF}$, (3) $-\mathrm{C}_{76} \mathrm{H}_{82} \mathrm{~N}_{4} \mathrm{O}_{12} \mathrm{Fe} \cdot \mathrm{BF}_{4}$.

Among the works published around the world there are only some in which the authors conducted

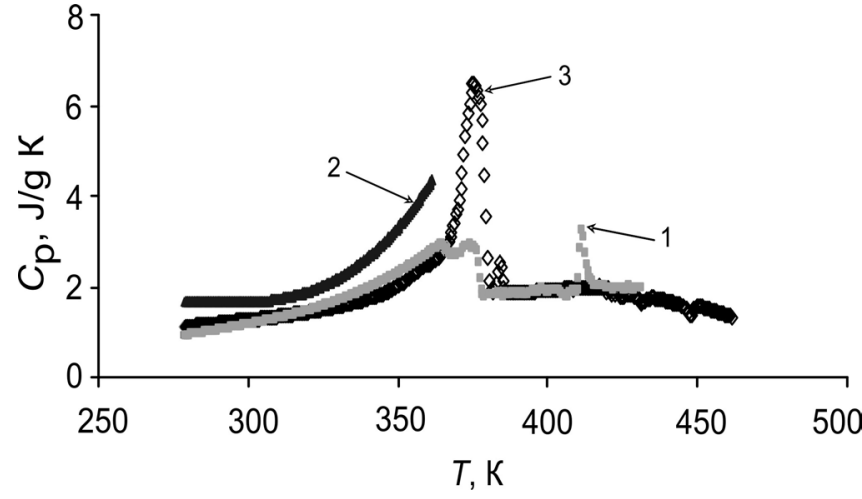

Fig. 7. Temperature dependence of specific heat capacity of complexes: (1) - $\mathrm{C}_{76} \mathrm{H}_{82} \mathrm{~N}_{4} \mathrm{O}_{12} \mathrm{Fe} \cdot \mathrm{NO}_{3}$, (2) $\mathrm{C}_{76} \mathrm{H}_{82} \mathrm{~N}_{4} \mathrm{O}_{12} \mathrm{Fe} \cdot \mathrm{PF}_{6},(3)-\mathrm{C}_{76} \mathrm{H}_{82} \mathrm{~N}_{4} \mathrm{O}_{12} \mathrm{Fe} \cdot \mathrm{BF}_{4}$

a theoretical study of magnetic phase transitions in spin-variable systems in the temperature range up to $100 \mathrm{~K}$. Work [54] established a correlation between thermotropic mesomorphism and magnetic phase transition in the complexes.

According to the DSC (Fig. 7) and ESR [55] data, there are no phase transitions in the range of $270-360 \mathrm{~K}$ in the complexes. However, $\mathrm{f}\left(C_{\mathrm{p}}\right)$ has maxima at higher temperatures (complex 1 at 365,375 and $410 \mathrm{~K}$, complex 3 - at 375 and $383 \mathrm{~K})$. It is probably the specific procedure of the DSC and ESR methods (scanning at certain intervals) and magnetothermal method (keeping a sample at a certain temperature for 4-10 hours) that leads to a shift of the specific heat capacity and absence of maxima in the room temperature region on the ESR curves. The specific heat capacity of the samples at zero magnetic fields (Fig. 7) increases as the temperature becomes higher and is equal to $4.3 \mathrm{~J} / \mathrm{g} \mathrm{K}$ for sample 2, 2.7 $\mathrm{J} / \mathrm{g} \mathrm{K}$ for sample 1 and $25 \mathrm{~J} / \mathrm{g} \mathrm{K}$ for sample 3 at $360 \mathrm{~K}$. No effect of the magnetic field on the temperature dependence is observed. Therefore, we do not show the temperature dependence of specific heat capacity in magnetic field here.

The specific features of the structure of the obtained complexes consisted in the positive values of magnetocaloric effect under the action of magnetic field. In the temperature range of 280 - $320 \mathrm{~K}$, the MCE dependences were extremal, which allowed the authors to suppose a firstorder magnetic phase transition (Fig. 9) [54]. The experimentally obtained MCE values of the complexes were positive when magnetic field was 


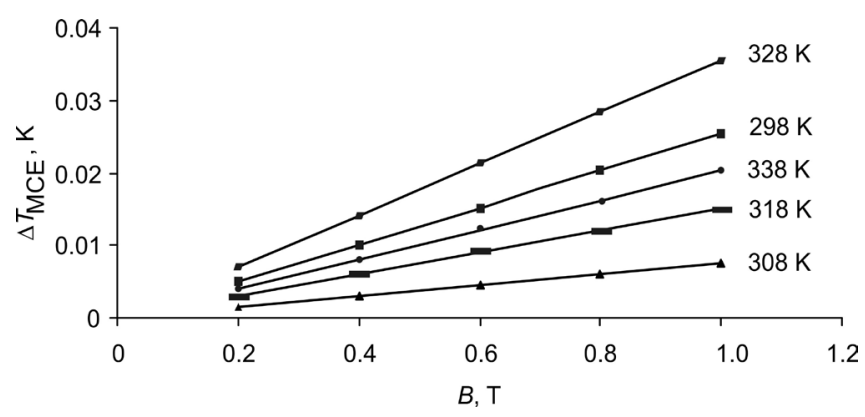

Fig. 8. Field dependence of magnetocaloric effect of complex 3 at different temperatures [54].

switched on and grew linearly as the magnetic induction increased (Fig. 8, for complexes 1 and 2, the dependences are analogous and are not given here).

The maximum MCE value was reached at the temperatures of magnetic phase transition, for example, in the region of Curie and Neel temperatures. Fig. 9 shows temperature dependences of MCE of the $\mathrm{BF}_{4}$ complex (3) characterized by an extremal dependence of MCE in the temperature range of $300-350 \mathrm{~K}$, probably due to the magnetic phase transition.

Phase transformations of complexes had been earlier studied by the method of polarization thermal microscopy [55]; it was established that all the substances under study displayed mesomorphic properties and were thermotropic liquid crystals. Analysis of the polarization thermal microscopy and microcalorimetry results shows that there is a correlation between magnetic phase transition and thermotropic mesomorphism. For example, according to the thermal microscopy data, the complex with a $\mathrm{BF}_{4}^{-}$counter-ion forms a nongeometrical texture at a temperature of 370 $\mathrm{K}$ and later turns into a nematic at about $411 \mathrm{~K}$

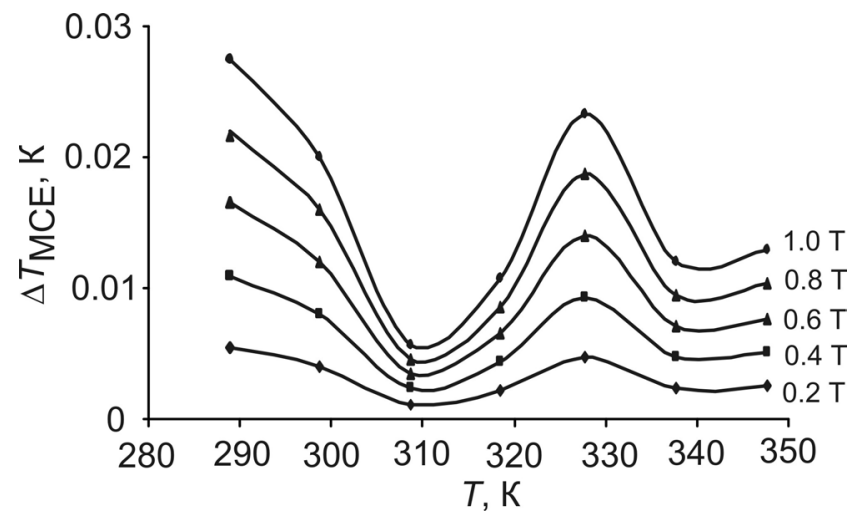

Fig. 9. Temperature dependence of magnetocaloric effect of complex 3 at different magnetic fields.
[54]. Complete destruction of the sample begins at about $425 \mathrm{~K}$. The expected magnetic phase transition is observed at the temperature below the phase transition crystal - mesotropic phase (at $308 \mathrm{~K}$ ). The complex character of the MCE temperature dependence, probably, indicates a stepwise magnetic phase transition in the sublattice of the complexes.

In order to further study the magnetothermal properties of iron(III) coordination compounds which have mesomorphic and spin-variable properties at the same time, we have tried to modify the paramagnetic ion local environment. It was supposed that this approach would allow combining the liquid crystal state and the properties of the spin-crossover in one temperature range. A new iron(III)-containing complex based on 3,4,5-tri(tetradecyloxy) benzoyloxy-4-salicylideneN'-ethyl-N-ethylenediamine $\left(\mathrm{C}_{120} \mathrm{H}_{206} \mathrm{~N}_{4} \mathrm{O}_{12} \mathrm{FePF}_{6}\right.$ (II.1)) has been synthesized [56]. An experimental study of magnetothermal properties of the obtained complex was carried out in magnetic field from 0 to $1.0 \mathrm{~T}$ at a temperature of $293 \mathrm{~K}$. Based on the analysis of the results obtained above, it was supposed that all azomethine iron(III) complexes were capable to display MCE. This hypothesis is based on the Mössbauer spectroscopy data which showed that the iron(III) ion was in a high-spin state at the temperature $T \geq 80 \mathrm{~K}$; polarization thermal microscopy data which indicated that the complexes had phase transitions; and differential scanning calorimetry data confirming the hypothesis $[55,56]$. To confirm these hypotheses, we carried out an experimental study of the magnetocaloric effect of the new synthesized complex when the magentic field changed from 0 to $1.0 \mathrm{~T}$ at a temperature of $293 \mathrm{~K}$. However, contrary to expectations, we found that when the magnetic field was switched on, the complex did not display any magnetocaloric effect. Probably, the formation of an azomethine chelate due to the interaction of the N-ethylenediamine fragment with aldehydes excludes $\pi$ - $\pi$-stacking between the molecules of the complexes, which leads to the repulsion of the molecules' octahedrals, coordination spheres of iron ions. The obtained 
complex, due to its structure, probably displays $\mathrm{MCE}$ in another temperature range.

\section{MCE IN GRAPHENE AND OTHER CARBON NANOFORMS}

The computational and experimental works of the last decade have shown that the specific features of the electronic structure of carbon-containing samples can lead to the development of magnetic (including ferromagnetic) or superconductive electronic correlations that do not disappear till room temperature is reached [57]. For example, there are report about ferromagnetic ordering in samples based on fullerenes [58].

A special place among carbon nanostructures is taken by graphene - a layer of $s p^{2}$-carbon atoms in the form of a hexagonal 2D lattice. Graphene attracts the attention of both theorists and experimentalists with its combination of unique properties caused by the behaviour of its $\pi$-electron system determining its high electrophysical characteristics and mechanical strength [59].

Although magnetic ordering in graphene samples of different origins has been observed a numberof times, themechanism of ferromagnetism in such carbon nanostructures is still unclear; however, there is an evident connection between magnetism and defects of different nature in the studied graphene samples [60]. Defects in graphene can be divided into several types [61]: structural defects caused by the presence of "pentagons" or "hexagons"; substitution of C atoms with other atoms in the hexagonal crystal lattice (for example, $\mathrm{N}$ and $\mathrm{P}$ ); defects that are not caused by $s p^{2}$-bonds of carbon atoms (vacancies, breakage of edge bonds, adsorbed atoms, interstitial atoms, deformation of graphene sheets, etc.).

It is noted that along the perimeter of some of the graphene flakes, carbon atoms are in specific edge states with dangling bonds: "armchair", "zigzag" and "beard" [60]. Unsaturated valence bonds at the edge of graphene flakes are filled with stabilizing elements. It is usually believed that "zigzag" is stabilized by one hydrogen atom. A "bearded" edge is bonded to two hydrogen atoms. There is a great difference between the electron states depending on the edge shape. These differences are directly connected with magnetic ordering. For example, Fujita [62] applying the Hubbard model, supposed that $\pi$-electrons on a "zigzag" edge can produce a ferromagnetic spin system. However, graphene structures of the "armchair" type have no localized states. The structure of the perimeter of arbitraryshaped graphene flakes is normally described as a combination of zigzag- and armchair edges. Edge states with a poorly developed zigzag structure consisting of three or four teeth significantly change the electron structure.

If both edges of a graphene tape are zigzagshaped or bearded, the total spin momentum of the graphene tape is equal to zero as the $\pi$-electron system produces a two-sublattice structure with the same number of positions in the sublattices, i.e. the local magnetic moments at the edges interact antiferromagnetically.

Such edge effects are strongly dependent on the medium into which the sample under study is placed. For example, hydrogen trapping by dangling bonds along the graphene perimeter can induce finite magnetization or suppress it. A theoretical study of a graphene tape in which every carbon is linked with 2 hydrogen atoms on one edge (bearded edge) and with a single hydrogen atom on the other edge (zigzag edge) has shown that the structure has a finite total magnetic moment: a double lattice is formed with a different number of positions in each sublattice [63].

The unusual magnetism of graphene has been predicted theoretically [64] and observed experimentally $[65,66]$ in carbon material nanocrystals representing a stack of graphene layers. There is a significant difference in the magnetic behavior of nanographite systems depending on the order of graphene plane positions. A layer displacement by half of a cell value leads to finite magnetization of the sample.

Thus, above we have considered some of the variants of appearance of magnetic ordering in the samples of graphene of different origins and shown that all of them are associated with defects of its structure.

So far, we have found only several theoretical works about MCE in graphene at low temperatures. 
For example, works [67, 68] describe oscillatory magnetocaloric and electrocaloric effects and the influence of longitudinal electric field on graphene magnetocaloric properties, respectively. Entropy changes have two contributions, and the temperature at which the entropy changes most of all goes down because of the electric field applied.

MCE can be usually identified by changes in the magnetic state of a magnetic material caused by external magnetic field variations. As it has been mentioned before, depending on conditions of magnetic field application, for quantitative characterization of MCE is usually used either the adiabatic change in the temperature $\Delta T_{\mathrm{MCE}}$, or the isothermal decrease in the entropy $\Delta S_{\mathrm{m}}$ and heat release $Q_{\mathrm{MCE}}$ associated with it. Heat capacity of a material as a function of field and temperature is the third most important parameter showing the material ability to accumulate thermal energy.

Work [69] reports the results of recent studies which found an earlier unknown magnetocaloric effect of flaked multi-layer graphene in the range of room temperatures. Changes in graphene temperature under the action of magnetic field are associated with specific features of its electronic structure and chemical composition.

In this work, magnetic ordering was confirmed by observing MCE of the graphene samples experimentally (reduced graphene oxide RGO) under study.

When the magnetic field induction changed from 0 to $0.1 T$, the magnetocaloric effect was positive. The MCE dependence on field was linear (Fig. 10). At $298 \mathrm{~K}$, the MCE values were equal to $0.025 \mathrm{~K}$. The graphene samples obtained by different methods had different degrees of surface imperfection. As a result, it was established that as

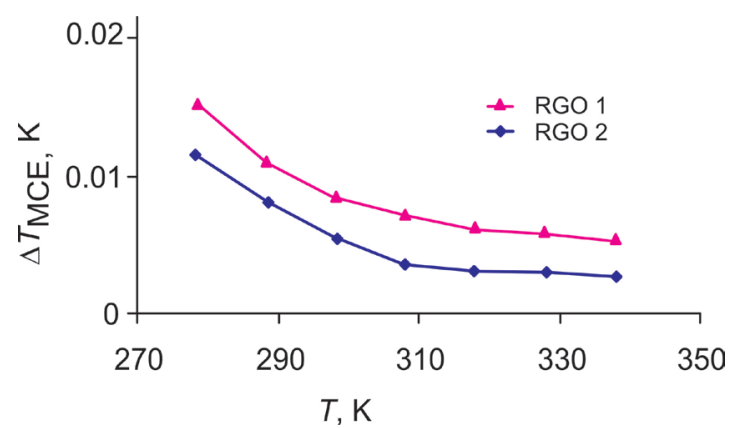

Fig. 10. Temperature dependence of MCE in graphene (RGO 1 and RGO 2) in magnetic field of $1.0 \mathrm{~T}$.

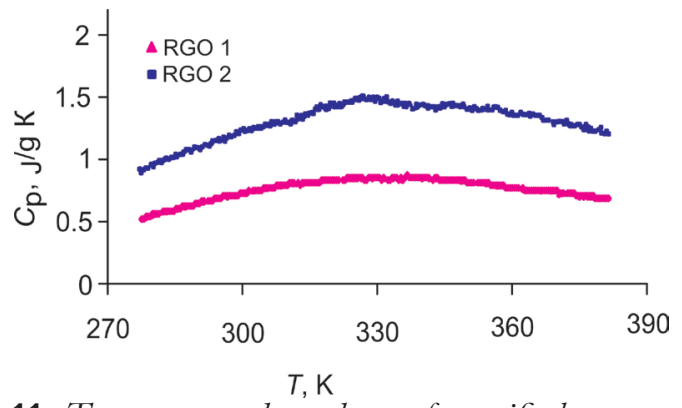

Fig. 11. Temperature dependence of specific heat capacity of graphene (RGO 1/RGO 2) in the zero magnetic field. the graphene surface imperfection became greater, the MCE increased.

As is known, specific heat capacity is a parameter sensitive to the structure of an object and, thus, the DSC analysis of the samples has shown that $C_{\mathrm{p}}$ has different values for the graphene samples with different imperfection degrees. In the range of room temperatures, the values of specific heat capacity of both graphene samples are about $1 \mathrm{~J} / \mathrm{g}$ $\mathrm{K}$. As the graphene samples' surface imperfection degree becomes greater (Fig. 11), the heat capacity decreases.

A certain place among the carbon-containing materials capable of magnetocaloric effect is taken by compounds based on porphyrins and phthalocyanines (Section 3). Magnetothermal properties of chain and macrocyclic singlemolecule magnets of the porphyrin and phthalocyanine types found on the graphene surface have not been studied earlier; there is no literature data about direct measurements of MCE and heat capacity in magnetic fields.

There are a number of works describing the processes of obtaining graphene composites with porphyrins and phthalocyanines. Work [70] reports a method of obtaining a complex of TMPyP and CCG graphene as a result of supramolecular assembly in an aqueous environment (Fig. 12).

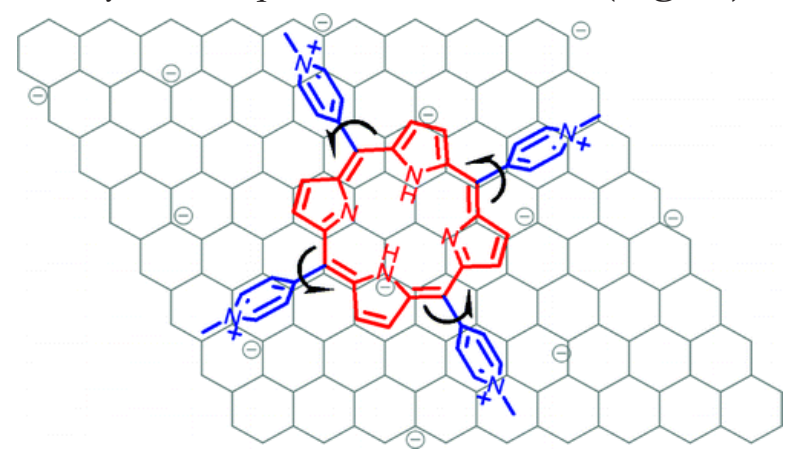

Fig. 12. Structure of the TMPyP/graphene CCG complex [70]. 
The electrostatic interaction led to a strong compression of the porphyrin on the graphene surface confirmed by a red (bathochromic) shift of the porphyrin Soret band. The authors believe that the TMPyP/graphene CCG complex can be used as a new optical sensor with high sensitivity and selectivity for cadmium ions. In work [71], a composite of reduced graphene oxide (RGO) and copper phthalocyanine tetrasulfonate $\mathrm{CuPc}\left(\mathrm{HSO}_{3}\right)_{4}$ was obtained. The composite films have lower conductivity but much higher photoconductivity and photosensitivity.

In 2014, Haiou Zhu [72] published a work which described flexible graphene superlattices synthesized by them and consisting of backbones of alternating layers of intercalated vanadium oxide $\mathrm{VO}_{2}$ and graphene. As a result of electrodonor and deformation effects, the lattice nanostructures display MCE. The maximum value of $\Delta S_{\mathrm{m}}$ in the point of phase transition at a temperature of $240 \mathrm{~K}$ when the magnetic field changes to $1.5 \mathrm{~T}$ is equal to $0.4 \mathrm{~J} / \mathrm{kg} \mathrm{K}$, which is much higher than the MCE at the phase transition temperature of pure $\mathrm{VO}_{2}$.

Soft molecular low-temperature ferromagnetism was observed and studied for n-doped fullerenes obtained when the fullerene was affected by strong organic reducing agents, such as tetrakis(dimethylamino)ethylene [73].

Creating magnetic clusters and hybrids [74, $75]$ is one of the ways to increase spin density in SMMs [76] and, in general, to improve magnetic properties. In some cases, when there are additional centres with an uncompensated spin in the molecular structure [77, 78], the MCE increases. Molecular forms of carbon, namely fullerene and its functional derivatives, attract the attention of a lot of scientists and engineers because they have high electron transfer characteristics, long-lived charge-separated states, high mobility of carriers and chemical stability $[79,80]$. For example, metalloporphyrin-fullerene dyades collected through axial donor-acceptor coordination have been studied in the process of photo-induced electron transfer with acceptable parameters of photocurrent and IPCE [81-83]. Recent studies [84] described below have shown the first experimental data about the existence of MCE in $\mathrm{C}_{60}$ in the room temperature range associated with fullerene antiaromaticity. The aim of study [84] represented in this work was to confirm the magnetocaloric effect and obtain magnetocaloric parameters in the porphyrinfullerene conjugate built via axial donor-acceptor coordination of the pyridyl substituent in fullero[60]pyrrolidine with the central cobalt atom in the porphyrin complex. To achieve this, the authors directly determined the thermodynamic parameters of MCE and specific heat capacity of [60] fullerene $\left(\mathrm{C}_{60}\right), 1^{\prime}$-N-methyl-2'-(pyridine4-yl) pyrrolidino[3',4':1,2][60]fullerene $\left(\mathrm{PyC}_{60}\right)$, $5,10,15,20$-(tetra-4-tret-butylphenyl) $21 \mathrm{H}$, 23H-porphynato)cobalt(II) (Co ${ }^{\text {IITBPP) }}$ and the triad $\left(\mathrm{PyC}_{60}\right)_{2} \mathrm{Co}^{\mathrm{II}} \mathrm{TBPP}$. The MCE and specific heat capacity were obtained by the original microcalorimetric method [28] and by the method of differential scanning calorimetry (DSC), respectively. As a result, it was shown that the precursors under study and the triad demonstrated a positive magnetocaloric effect at room temperature when the magnetic induction changed from zero to $1.0 \mathrm{~T}$.

By determining the thermodynamic parameters of MCE and specific heat capacity for the donoracceptor triad in comparison with the fullerene $\mathrm{C}_{60}$ and precursors directly by the microcalorimetric method developed by us [28] and by the DSC, respectively, we have shown that carbon nanoforms $\mathrm{C}_{60}, \mathrm{PyC}_{60}$, porphyrin complex and the triad have positive MCE values of $0.004,0.016,0.028$ and $0.007 \mathrm{~K}$, respectively, at $278 \mathrm{~K}$ and magnetic field induction of $1.0 \mathrm{~T}$ (Fig. 13).

The magnetocaloric effect decreases at the formation of the donor-acceptor triad in comparison with $\mathrm{PyC}_{60}$ and $\mathrm{Co}^{\mathrm{II}} \mathrm{TBPP}$ but also leads to the appearance of new interesting properties, namely photo-induced electron transfer. Based on the temperature dependences of the thermodynamic parameters - specific heat $\left(Q_{\mathrm{MCE}}\right)$, enthalpy change $(\Delta H)$, entropy change $(\Delta S)$ and specific heat capacity, the increase in the MCE following fullerene substitution $\left(\mathrm{C}_{60} \rightarrow \mathrm{PyC}_{60}\right.$ transition) can be explained by the regions of aromaticity and 


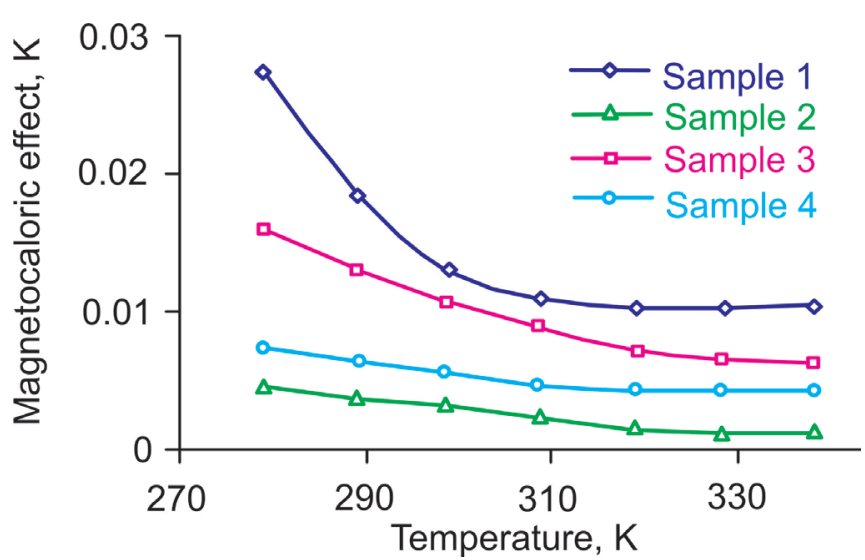

Fig. 13. Temperature dependences of MCE of the samples in magnetic field of $1.0 \mathrm{~T}$ : sample 1 - Co IITBPP; sample 2 - $C_{60}$; sample $3-P y C_{60}$ s sample $4-\left(P y C_{60}\right)_{2} C 0^{I I}$ TBPP. The experimental error in the MCE measurements was 2\% [84].

antiaromaticity in the fullerene. The decrease in the MCE of the triad, $\left(\mathrm{PyC}_{60}\right)_{2} \mathrm{Co}^{\mathrm{II}} \mathrm{TBPP}$, in comparison with the precursors $\mathrm{PyC}_{60}$ and $\mathrm{CO}^{\mathrm{II}} \mathrm{TBPP}$ is caused by higher specific heat capacity of the triad (Fig. 14). This fact shows good prospects for the transition from tetracoordinated complexes $\mathrm{Co}^{\mathrm{II}} \mathrm{TBPP}$ to pentacoordinated porphyrin complexes of metals with a non-zero spin, in which there is only one axial coordination position for binding the substituted fullerene.

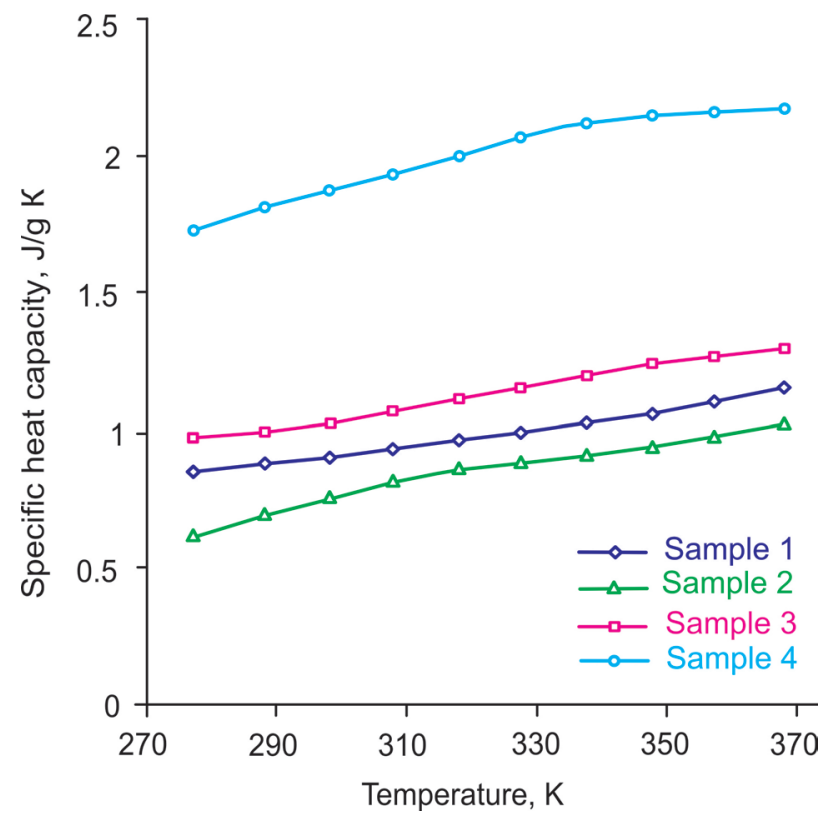

Fig. 14. Temperature dependences of specific heat capacity of the samples in zero magneticfield: sample 1-Co IITBPP; sample $2-C_{60}$; sample $3-P y C_{60}$; sample $4-\left(P y C_{60}\right)_{2} C^{I I} T B P P$ (DSC data, experimental error 1.5\%) [84].

\section{CONCLUSION}

Thus, the data presented above, allow us to make the following conclusions. Since the data on magnetic and magnetocaloric properties of graphene, fullerene, porphyrins, phthalocyanines are fragmentary, they require systematic studies in order to create, based on them, a series of new materials with non-standard magnetic and electrooptical characteristics.

The mechanism of ferromagnetism in carbon nanostructures, and in graphene in particular, is not clear yet. However, it is now evident that there is a connection between magnetism in graphene and defects in its structure.

The analysed quantitative data allow determining the positive contributions (separation in the ligand field; delocalization of spin density) to the magnetic behaviour of rare earth elements with porphyrins/phthalocyanines along with the negative ones (mass and specific heat capacity increase; interaction of spin-carriers with nuclear spins, higher strength of the bonds with the macrocycle); depending on the electronic configuration of the central atom - metal-to-ligand $\pi$-back donation.

In conclusion, it should be said that the method of microcalorimetry allows determining the presence or absence of magnetic phase transition in single-molecule magnets and even now characterizing the behavior of materials at temperatures close to room conditions.

\section{ACKNOWLEDGMENTS}

The review was prepared at the Institute of Solution Chemistry of the RAS as a part of a Government assignment, project "Scientific and technical bases of obtaining functional materials and nanocomposites" (a theme of plans No. 0092-2014-0002 and 0092-20170003) on the Centre for Joint Use of Scientific Equipment "The Upper Volga Region Centre of Physicochemical Research" and was partially financed by a grant of the Russian Foundation for basic Research (project 18-43-370022-p-a).

\section{REFERENCES}

1. Murtaza Bohra, Sahoo SC. Large magnetocaloric effect at Verwey point in nanocrystalline $\mathrm{Fe}_{3} \mathrm{O}_{4}$ thin films. J. Alloys. Compd., 2017, 699:1118-1121. 
2. Jing Zhong, Wenzhong Liu, Ling Jiang, Ming Yang, Paulo Cesar Morais. Real-time magnetic nanothermometry: The use of magnetization of magnetic nanoparticles assessed under low frequency triangle-wave magnetic fields. Rev. Sci. Instrum., 2014, 85:094905. DOI:10.1063/1.4896121.

3. Despoina Sakellari, Mathioudaki Stella, Zoi Kalpaxidou, Konstantinos Simeonidis, Makis Angelakeris. Exploring multifunctional potential of commercial ferrouids bymagnetic particle hyperthermia. JMMM, 2015, 380:360.

4. Nemala H, Thakur JS, Naik VM, Vaishnava PP, Lawes $G$, Naik R. Investigation of magnetic properties of $\mathrm{Fe}_{3} \mathrm{O}_{4}$ nanoparticles using temperature dependent magnetic hyperthermia in ferrofluids. J. Appl. Phys., 2014, 116:034309. DOI: $10.1063 / 1.4890456$.

5. Pełka R, Gajewski M, Miyazaki Y. Magnetocaloric effect in $\mathrm{Mn}_{2}$-pyrazole$\left[\mathrm{Nb}(\mathrm{CN})_{8}\right]$ molecular magnet by relaxation calorimetry. JMMM, 2016, 419:435. DOI: org/10.1016/j.jmmm.2016.06.074.

6. Buchachenko AL. Organicheskie i molekulyarnye ferromagnetiki: dostizheniya i problemy [Organic and Molecular Ferromagnetics: Achievements and Challenges]. Uspekhi khimii, 1990, 59(4):529550 (in Russ.).

7. Sessoli R, Gatteschi D, Caneschi A, Novak MA. Magnetic bistability in a metal-ion cluster. Nature, 1993, 365:141-144.

8. Ovcharenko VI, Sagdeev RZ. Molekulyarnye ferromagnetiki [Molecular Ferromagnetics]. Uspekhi Khimii, 1999, 68(5):381-400 (in Russ.).

9. Tretyakov EV, Ovcharenko VI. Khimiya nitroksilnyx radikalov v molekulyarnom dizaine magnetikov [Chemistry of nitroxyl radicals in molecular design of magnets]. Uspekhi khimii, 2009, 78(11):1051-1093 (in Russ.).

10. Lukov VV, Kogan VA, Cherbakov IN, Popov LD, Levchenko SI. Molekulyarnye magnetiki: eksperimentalno-teoreticheskie osnovy dizaina magnitnikh materialov buduyushchego [Molecular Magnets: Experimental and Theoretical Foundations of the Design of
Magnetic Materials of the Future]. Vestnik Yuzhnogo NC RAN, 2011, 7(1):24-41 (in Russ.).

11. Evangelisti M, Roubeau O, Palacios E, Camon A, Hooper TN, Brechin EK, Alonso JJ, Cryogenic Magnetocaloric Effect in a Ferromagnetic Molecular Dimer. Angew. Chem. Int. Ed., 2011, 50:6606-6609.

12. Torres F, Bohigas X, Hernandez JM, Tejada J. Magnetocaloric effect in $\mathrm{Mn}_{12}$ 2-Cl benzoate. J. Phys.: Condens. Matter., 2003, 15:L119-L123. DOI: stacks.iop.org/JPhysCM/15/L119.

13. Sharples JW, Zheng Y-Zh, Tuna F, McInnesand EJL, Collison D. Lanthanide discs chill well and relax slowly. Chem. Comm., 2011, 47:7650-7652.

14. Schnack J, Schmidt R, Richter J. Enhanced magnetocaloric effect in frustrated magnetic molecules with icosahedral symmetry. Phys. Rev. B, 2007, 76:054413.

15. Zheng Y, Molybdate templated assembly of $\mathrm{Ln}_{12} \mathrm{Mo}_{4}$-type clusters ( $\mathrm{Ln}=\mathrm{Sm}, \mathrm{Eu}, \mathrm{Gd}$ ) containing a truncated tetrahedron core. Chem. Comm., 2013, 49:36-38.

16. Zheng Y-Zh. MnII-GdIII Phosphonate Cages with a Large Magnetocaloric Effect. Chem. Eur. J., 2012, 18:4161-4165.

17. Peng J-B. A 48-Metal Cluster Exhibiting a Large Magnetocaloric Effect. Chem. Int. Ed., 2011, 50:10649-10653.

18. Manoli M, Collins A, Parsons S, Candini A, Evangelisti M, Brechin EK. Mixed-valent Mn supertetrahedra and planar discs as enhanced magnetic coolers. I Am Chem Soc, 2008, 130:11129-11139.

19. Zhang Y. Review of the structural, magnetic and magnetocaloric properties in ternary rare earth $\mathrm{RE}_{2} \mathrm{~T}_{2} \mathrm{X}$ type intermetallic compounds. Journal of Alloys and Compounds, 2019, 787:1173-1186. https://doi.org/10.1016/j. jallcom.2019.02.175.

20. Ishikawa N, Sugita M, Wernsdorfer W. Quantum tunneling of magnetization in lanthanide single-molecule magnets: bis(phthalocyaninato) terbium and bis(phthalocyaninato) dysprosium anions. Angew Chem Int Ed, 2005, 44: 2931-2935.

21. Pełka R, Konieczny P, Zieliński PM, Wasiutyński T, Miyazaki Y, Inaba A, Pinkowicz 
D, Sieklucka B. Magnetocaloric effect in $\left.[\mathrm{Fe} \text { (pyrazole })_{4}\right]_{2}\left[\mathrm{Nb}(\mathrm{CN})_{8}\right] \cdot 4 \mathrm{H}_{2} \mathrm{O}$ molecular magnet. JMMM, 2014, 354:359-362.

22. Fitta M, Bałanda M, Mihalik M, Pełka R, Pinkowicz D, Sieklucka B, Zentková M. Magnetocaloric effect in M-pyrazole$\left[\mathrm{Nb}(\mathrm{CN})_{8}\right](\mathrm{M}=\mathrm{Ni}, \mathrm{Mn})$ molecular compounds. J. Phys.: Condens. Matter, 2012, 24(50):506002.

23. Monteiro B, Coutinho JT, Pereira LCJ. Heterometallic 3d-4f SMMs (in LanthanideBased Multifunctional Materials From OLEDs to SIMs). Advanced Nanomaterials, 2018, 42:233-261.

24. Caracciolo F, Mannini M, Poneti G, Pregelj M, Janša N, Arčon D, Carretta P. Spin fluctuations in the light-induced high-spin state of cobalt valence tautomers. Phys. Rev. B, 2018, 98:054416.

25. Kharisov BI, Kharissova OV (Ed.) Carbon Allotropes: Metal-Complex Chemistry, Properties and Applications. Springer, 2019, 350 p., https:// doi.org/10.1007/978-3-030-03505-1.

26. Wang WL, Sheng Meng, Efthimios Kaxiras. Graphene NanoFlakes with Large Spin. Nano Letters, 2008, 8(1):241-245.

27. Sarkar SK, Raul KK, Pradhan SS, Basu S, Nayak A. Magnetic properties of graphite oxide and reduced graphene oxide. Physica E, 2014, 64:78-82, https://doi.org/10.1016/j. physe.2014.07.014.

28. Korolev VV, Korolev DV, Ramazanova AG. The calorimetric method of evaluating the performance of magnetocaloric materials. Journal of Thermal Analysis and Calorimetry, 2019, 136(2):937-941; doi: 10.1007/ s10973-018-7704-y.

29. Sharples JW, Collison D. Reprint of "Coordination compounds and the magnetocaloric effect". Polyhedron, 2013, 66:15.

30. Korolev VV, Lomova TN, Maslennikova AN, Korolev DV, Shpakovsky DB, Zhang J, Milaeva ER. Magnetocaloric properties of manganese(III) porphyrins bearing 2,6-di-tertbutylphenol groups. JMMM, 2016, 401:86.

31. Korolev VV, Lomova TN, Korolev DV, Ramazanova AG, Mozhzhuhkina EG, OvchenkovaEN. Newnanoscaled paramagnetic complexes (NPCs) based on Porphyrins/ Phthalocyanines for environmental chemistry [In: RSC Detection Science Advanced Environmental Analysis Applications of Nanomaterials] Ed. Hussain CM, Kharisov B, Cambridge, Royal Society of Chemistry, 2016, v. 2, 526 p.

32. Korolev VV, Lomova TN, Ramazanova AG, Korolev DV, Mozhzhuhkina EG. Phthalocyanine-based molecular paramagnets. Effect of double-decker structure on magnetothermal properties of gadolinium complexes. Organometallic Chemistry, 2016, 819:209.

33. Korolev VV, Lomova TN, Ramazanova AG, Mozhzhuhkina EG. Phthalocyaninato lanthanide (III) acetates as a new class of molecular paramagnets with large magnetocaloric effect. Mendeleev Commun., 2016, 26:301.

34. Korolev VV, Lomova TN, Ramazanova AG, Mozhzhuhkina EG. Molecular paramagnets. The effect of structural modification on (porphyrinato) gadolinium(III) magnetothermal properties. Synthetic Metals, 2016, 220:502.

35. Korolev VV, Lomova TN, Klyueva ME, Arefyev IM, Zakharov AG, Korolev DV. Magnetokaloricheskiy effect i teploemkost visokospinovykh kompleksov margantsa $\mathrm{v}$ visokodispersnom sostoyanii [Magnetocaloric effect and heat capacity of high-spin manganese complexes in a dispersed state]. Zhurnal firicheskoy khimii, 2010, 84(9):1785 (in Russ.).

36. Korolev VV, Lomova TN, Arefyev IM, Ovchenkova EN, Klyueva ME, Zakharov AG, Korolev DV. Magnitoteplovye svoystva zameshchenogo margantsa(III) vodnoy suspenzii [Magnetothermal properties of substituted (tetraazoporfinato) manganese (III) aqueous suspension]. Zhurnal fizicheskoy khimii, 2012, 86(7):1285 (in Russ.).

37. Korolev VV, Klyueva ME, Arefyev IM, Ramazanova AG, Lomova TN, Zakharov AG. Regularities of magnetocaloric effect and determining some thermodynamic parameters 
for $(2,3,7,8,12,13,17,18$-octaethylporphynato $)$ chloromanganese(III). Macroheterocycles, 2008, 1(1):68.

38. Korolev VV, Arefyev IM, Klyueva ME, Lomova TN. Use of magnetocaloric effect for direct experimental determining some thermodynamic parameters of manganese(III) porphyrin. J Porphyrins Phthalocyanines, 2008, 12(3-6):584.

39. Lomova TN, Korolev VV, Zakharov AG. Central atom/substituent effects on magnetothermal properties of metal porphyrins in aqueous suspension. Materials Science \& Engineering B, 2014, 186:54-63.

40. Lomova TN, Korolev VV, Ramazanova AG, Ovchenkova EN. Magnetothermal properties of (octakis-trifluoromethylphenyltetraazapo rphinato) manganese(III) acetate in aqueous suspension. J Porphyrins Phthalocyanines, 2015, 19:1262.

41. Korolev VV, Korolev DV, Lomova TN, Mozhzhuhkina EG, Zakharov AG. Magnitokaloricheskiy effect i teploemkost vodnikh suspenziyi porfirinovykh kompleksov redkozemelnykh elementov iz mikrokalorimetricheskikh dannykh [Magnetocaloric effect and heat capacity of aqueous suspensions of porphyrin complexes of rare-earth elements from microcalorimetric data]. Zhurnal fizicheskoy kbimii, 2012, 86(3):578582 (in Russ.).

42. Lomova TN, Andrianova LG, Berezin BD. Mekhanizm dissotsiatsii i kineticheskaya ustoychivost tetrafenilporfinovykh kompleksov lantanoidov ot samariya do lutetsiya [The mechanism of dissociation and kinetic stability of lanthanide tetraphenylporfin complexes from samarium to lutetium]. Zhurnal firicheskoy kbimii, 1987, 61(11):2921 (in Russ.).

43. Binnemans K, Galyametdinov YG, Van Deun R, Bruce DW, SR Collinson SR. Rare-earthcontaining magnetic liquid crystals. J Am. Chem. Soc., 2000, 122:4335-4344.

44. Galyametdinov Yu, Ksenofontov V, Prosvirin A, Ovchinnikov I, Ivanova G, Gütlich P, Haase W. First Example of Coexistence of Thermal
Spin Transition and Liquid-Crystal Properties. Angew. Chem. Int. Ed., 2001, 40(22):4269-4271.

45. Belarbi Z, Sirlin C, Simon J, André JJ. Electrical and magnetic properties of liquid crystalline molecular materials: Lithium and lutetium phthalocyanine derivatives. J Phys. Chem., 1989, 93:8105-8110.

46. Khoo I-C. Liquid crystals. Wiley Inc., 2007, 368 p. 47. Bruce DW, Dunmur DA, Hunt SE, Maitlis P.M., Orr R. Linear Dichroism of Mesomorphic TransitionMetal Complexes of Alkoxydithiobenzoates. J. Mater. Chem., 1991, 1:857-861. DOI: 10.1039/JM9910100857.

48. Barberá J, Levelut A-M, Marcos M, Romero P, Serrano JL. X-ray diffraction study of some mesogenic copper, nickel and vanadyl complexes Liquid crystals, 1991, 10:119-126; doi: 10.1080/02678299108028235.

49. Bousseksou A, Nasser J, Linares J, Boukheddaden K, Varret F. Ising-like model for the twostep spin-crossover. Journal de Physique I, 1992, 2(7):1381-1403.

50. Spiering H, Kohlhaas T, Romstedt H, Hauser A, Bruns-Yilmaz C, Kusz J, Gütlich P. Correlations of the distribution of spin states in spin crossover compounds Coordination Chemistry Reviews, 1999, 190-192:629-647.

51. Torayama H, Nishide T, Asada H, Fujiwara M, Matsushita T. Preparation and characterization of novel cyclic tetranuclear manganese(III) complexes: $\mathrm{MnIII}_{4}\left(\mathrm{X}\right.$-salmphen) ${ }_{6}$ (X-salmphen $\mathrm{H}_{2}=\mathrm{N}, \mathrm{N}$ '-disubstituted-salicylidene-1,3diaminobenzene $(\mathrm{X}=\mathrm{H}, 5-\mathrm{Br}))$. Polyhedron, 1998, 16(21):3787-3794.

52. Kalwania GS, Mathur R, Shyam R, Mathur P, Mathur SP. Spectrophotometeric determination of iron (III) with Schif's base derived from pyridine -2-carboxaldehyde and 2-aminopyrimidine by adsorption on Polyurethane. Journal of Natura Conscientia, 2010, 1(3):240-242.

53. Saxena A, Koacher JK, Tandon JP. Electronimpact Induced Fragmentation Studies on Some Diorganotion Complexes of S-Containing Schiff Bases. Inorg. Nucl. Chem. Lett., 1981, 17(778):229-233. 54. Gruzdev MS, Korolev VV, Ramazanova AG, Chervonova UV, Balmasova OV. Magnetocaloric Properties of Dendrimer 
Complexes of Fe(III) with Substituted Schiff Base. Liquid Crystals, 2018, 45(6):907-911.

55. Gruzdev M, Chervonova U, Zharnikova $\mathrm{N}$, Kolker A. Mesomorphic azomethine complexes of Iron(III) based on 4,4'-dodecyloxybenzoyloxybenzoyl-4salicylidene-2-aminopyridine. Liquid Crystals, 2013, 40(11):1541-1549.

56. Chervonova UV, Gruzdev MS, Kolker AM, Akopova OB. Structure and phase transitions of azomethine biligand complexes of iron(III) based on 3,4,5-tri(tetradecyloxy)benzoyloxy4-salicylidene-N'-ethyl-N-ethylenediamine. J Structural. Chem., 2016, 57(3):478-490. DOI: 10.1134/S0022476616030094.

57. Gonzalez J, Guinea F, Vozmediano M. Electronelectron interactions in graphene sheets. Phys. Rev. B, 2001, 63(13):421.

58. Wood RA, Lewis MH, Lees MR, Bennington SM, Cain MG, Kitamura N. Ferromagnetic fullerene. J Phys.: Condens. Matter, 2002, 14(22):L385.

59. Avouris P. Graphene: Electronic and Photonic Properties and Devices. Nano Lett., 2010, 10(11):4285-4294.

60. Makarova TL. Magnitnye svoystva uglerodnykh struktur [Magnetic properties of carbon structures]. Fiqika $i$ tekhnika poluprovodnikov, 2004, 38(6):641-664 (in Russ.).

61. Gubin SP, Tkachev SV. Grafen i rodstvennye nanoformy ugleroda [Graphene and related carbon nanoforms]. M., LENAND Publ., 2015, 112 p.

62. Fujita M, Wakabayashi K, Nakada K, Kusakabe K. Peculiar localized state at zigzag graphite edge. J Phys. Soc. Japan., 1996, 65(7):1920-1923.

63. Kusakabe K, Maruyama M. Magnetic nanographite. Phys. Rev. B, 2003, 67:092406.

64. Harigaya K. Mechanism of magnetism in stacked nanographite. J Phys.: Condens. Matter., 2001, 13:1295-1302.

65. Shibayama Y, Sato H, Enoki T, Endo M. Disordered magnetism at the metal-insulator threshold in nano-graphite-based carbon materials. Phys. Rev. Lett., 2000, 84(8):1744.

66. Enoki T, Kawatsu N, Shibayama Y, Sato H, Kobori R, Maruyama S, Kaneko K. Magnetism of nano-graphite and its assembly. Polyhedron, 2001, 20(11-14):1311-1315.
67. Alisultanov ZZ, Reis MS. Oscillating magnetoand electrocaloric effects on bilayer graphenes. Solid State Communications, 2015, 206:17-21. DOI: 10.1016/j.ssc.2015.01.005.

68. Reis MS. Influence of longitudinal electric field on the oscillating magnetocaloric effect of graphenes. Solid State Communications, 2013, 161:19-22. DOI: 10.1016/J.ssc2013.03.002.

69. Korolev VV, Ramazanova AG, Balmasova OV, Soloveva AYu, Buslaeva EYu, Gubin SP, Gruzdev MS. Magnetocaloric effect in reduced graphene oxide. JMMM, 2019, 476:604-607.

70. Yuxi Xu, Lu Zhao, Hua Bai, Wenjing Hong, Chun Li, Gaoquan Shi. Chemically Converted Graphene Induced Molecular Flattening of 5,10,15,20-Tetrakis(1-methyl-4-pyridinio) porphyrin and Its Application for Optical Detection of Cadmium(II) Ions. J Am. Chem. Soc., 2009, 131(37):13491.

71. Anindarupa Chunder, Tanusri Pal, Saiful I Khondaker, Lei Zhai. Reduced Graphene Oxide/Copper Phthalocyanine Composite and Its Optoelectrical Properties. J Phys. Chem. C, 2010, 114:15129-15135.

72. Haiou Zhu, Chong Xiao, Hao Cheng, Fabian Grote, Xiaodong Zhang, Tao Yao, Zhou Li, Chengming Wang, Shiqiang Wei, Yong Lei, Yi Xie. Magnetocaloric effects in a freestanding and flexible graphene-based superlattice synthesized with a spatially confined reaction. Nature Communications, 2014, 3(5):3960. DOI: 10.1038/ncomms4960.

73. Allemand P-M, Khemani KC, Koch A, Wudl F, Holczer K, Donovan S, Grüner G, Thompson DJ. Organic molecular soft ferromagnetism in a Fullerene $C_{60}$. Science, 1991, 253(5017):301-303.

74. Idowu MA, Xego S, Arslanoglu Y, Mark J, Antunes E, Nyokong T. Photophysicochemical behaviour and antimicrobial properties of monocarboxy $\mathrm{Mg}$ (II) and $\mathrm{Al}(\mathrm{III})$ phthalocyanine-magnetite conjugates. Spectrochimica Acta, Part A, 2018, 193:407-414. DOI: $10.1016 /$ j.saa.2017.12.052.

75. Modisha P, Antunes E, Mack J, Nyokong T. Improvement of the Photophysical Parameters of Zinc Octacarboxy Phthalocyanine upon Conjugation to Magnetic Nanoparticles. 
International Journal of Nanoscience, 2013, 12:1350010-1350010-10. DOI: 10.1142/ S0219581X13500105.

76. Giménez-Agully N, de Pipaón CS, Adriaenssens L, Filibian M, Martínez-Belmonte M, Escudero-Adán EC, Carretta P, Ballester P, Galán-Mascarós JR. Single-Molecule-Magnet Behavior in the Family of $\left[\mathrm{Ln}(\mathrm{OETAP})_{2}\right]$ Double-Decker Complexes (Ln=Lanthanide, OETAP $=$ Octa (ethyl) tetraazaporphyrin). Chem. Eur. J., 2014, 20:12817-12825. DOI: 10.1002/chem.2014.02.869.

77. Fu X, Xu L, Li J, Sun X, Peng H. Flexible solar cells based on carbon nanomaterials. Carbon, 2018, 139:1063-1073. DOI: 10.1016/j. carbon.2018.08.017.

78. Lomova TN, Motorina EV, Klyuev MV. Donor-acceptor fullerene complexes based on metal porphyrins [Kharisov BI, editor CRC Concise Encyclopedia of Nanotechnology] London, CRC Press, 2015, p. 215-229.

79. Anikin MS, Tarasov EN, Kudrevatykh NV, Osadchenko VH, Zinin AV. About the role of Fe-ions in the formation of magnetocaloric effect in $\mathrm{H}_{\mathrm{o}}\left(\mathrm{Co}_{1-\mathrm{x}} \mathrm{Fe}_{\mathrm{x}}\right)_{2}$ compounds. Acta Physica Polonica A, 2015, 127:635-637. DOI: 10.12693/APhysPolA.127635.

80. Bichan NG, Ovchenkova EN, Kudryakova NO, Ksenofontov AA, Gruzdev MS, Lomova TN. Self-assembled cobalt(II)porphyrinfulleropyrrolidine triads via axial coordination with photoinduced electron transfer. New J Chem., 2018, 42:12449-12456. DOI: 10.1039/ C8NJ00887F.

81. Piskorsky VP, Korolev DV, Valeev RA, Morgunov RB, Kunitsyna EI. Physics and Engineering of permanent magnet. Ed. Kablov EN, Moscow, VIAM Publ., 2018, 359 p.

82. Prato M, Maggini M, Giacometti C, Scorrano G, Sandona G, Farnia G. Synthesis and electrochemical properties of substituted fulleropyrrolidines. Tetrahedron, 1996, 52:52215234. DOI: 10.1016/0040-4020(96)00126-3.

83. Bichan NG, Ovchenkova EN, Gruzdev MS, Lomova TN. Formation Reaction and Chemical Structure of a Novel Supramolecular Triad Based on Cobalt(II)
5,10,15,20-(Tetra-4-Tert-Butylphenyl)21H,23H-Porphyrin and 1-Methyl-2-(Pyridin4'-Yl)- 3,4-Fullero[60]Pyrrolidine. Rus. J Struct. Chem., 2018, 59:711-719. DOI: 10.1134/ S0022476618030320.

84. Lomova TN, Korolev VV, Bichan NG, Ovchenkova EN, Ramazanova AG, Balmasova OV, Gruzdev MS. New paramagnets based on nanocarbon and cobalt(II)porphyrin: Magnetocaloric effect and specific heat capacity. Synthetic Metals, 2019, 253:116-121, doi: 10.1016/j.synthmet.2019.05.004. 